\title{
Optimum Design of Reinforced Concrete Multi-Story Multi-Span Frame Structures under Static Loads
}

\author{
Serdar Ulusoy, Aylin Ece Kayabekir, Gebrail Bekdaş, and Sinan Melih Nigdeli
}

\begin{abstract}
The construction economy is one of the major goals of engineers and only an experienced engineer can make an economical design after several trial efforts. Whereas, the optimum design of structures can be found by using metaheuristic methods. Especially, the optimum design of reinforced concrete $(\mathrm{RC})$ structures is challenging since two materials with different price and behavior are used. In that case, the optimization problem is highly non-linear and the developed methods employing harmony search (HS) algorithm is effective to solve the problem in several random stages. As the numerical example, the method was tested for two-story two-span RC frames. The results show that the metaheuristic based methodology is feasible.
\end{abstract}

Index Terms-Reinforced concrete, frames, optimization, metaheuristic algorithms, harmony search.

\section{INTRODUCTION}

In the design of reinforced concrete (RC) structures, the dimension of structural elements is defined and the structural analyses are done in order to obtain internal forces. According to these forces, the design requirements are checked and the reinforcement design is done. In this process, there are structural rules according to the design codes. If a rule is not satisfied, the dimension of the elements must be changed and it means that the structural analyses for internal forces must be redone for statically indetermined structures. This process is only for a design. If the optimum design is needed to find as a goal of structural engineers, several trials must be done according to the experience of engineers. Whereas, this process can be automatically done by using iterative optimization techniques and this iterative search process may be shortened by using heuristic approaches.

The feasibility of metaheuristic methods has been proved by proposing optimization approaches for RC structures or members. In the developed studies, the dimensions of structural members are generally optimized for the minimization of the total cost of the structures. The nature inspired metaheuristic methods are used to randomly generate design variables (dimensions) according to the specific rules of the algorithms in order to converge to the

Manuscript received November 6, 2017; revised May 1, 2018.

Serdar Ulusoy is with the Yeditepe University/Department of Civil Engineering, Istanbul, Turkey (e-mail: serulusoy87@gmail.com).

Aylin Ece Kayabekir is with Istanbul University/ Department of Civil Engineering, Istanbul, Turkey (e-mail: cekayabekir@gmail.com).

Gebrail Bekdaş is with Istanbul University/ Department of Civil Engineering, Istanbul, Turkey (e-mail: bekdas@ @istanbul.edu.tr).

Sinan Melih Nigdeli is with Istanbul University/ Department of Civil Engineering, Istanbul, Turkey (e-mail: melihnig@istanbul.edu.tr). best solution quickly without entrapping to a local optimum solution. In this process, the design constraints (defined according to the design codes) are also considered.

Genetic algorithm (GA) is one of the oldest metaheuristic algorithm and uses the stages of the evolution theory like selection, crossover and mutation. Firstly, GA has been employed in the optimum design of beams [1], biaxial columns [2], frames [3]-[6], continuous beams [7], T-shaped beams [8] and various members [9]. Also, GA combined with sequential quadratic programming (SQP) technique for shape optimization [10], simulated annealing (SA) for continuous beams [11] and discretized form of the Hook and Jeeves method for RC flat slab [12]. SA was employed for multi objective optimization of RC frames by Paya et al. [13]. Perea et al. developed a hybrid method combining four methods like random walk, the descent local search, the threshold accepting and SA for optimum design of RC bridges [14].

The minimum embedded $\mathrm{CO}_{2}$ emission is also an objective in the optimization of RC members. By using SA [15] and Big Bang-Big Crunch (BB-BC) [16], two different methodologies aiming for the $\mathrm{CO}_{2}$ emission of $\mathrm{RC}$ members were developed.

The optimum design of retaining walls is also an optimum exercise and RC retaining walls have been an interest for metaheuristic algorithm by considering both geotechnical and structural limit states as design constraints. Some of the employed algorithms for RC retaining walls are SA [17], [18], BB-BC [19], Harmony Search (HS) [20] and Charged System Search (CSS) [21].

HS; the music inspired metaheuristic algorithm is also a popular one for optimum RC member design. The optimized RC members by employing HS are continuous beams [22], frames [23], T-shaped beam [24] and retaining walls [20].

In the present study, a modified HS proposal is presented for optimum design of RC frames including the detailed design of reinforcements. The optimization is done for static loading and the rules of ACI 318- Building Code Requirements for Structural Concrete [25].

\section{Methodology}

Harmony Search (HS) algorithm was developed by Geem et al. [26] formulized the music performance of musicians which the best harmony is searched. Recently, HS has been employed in several structural engineering optimization problems such as cellular beams [27], trusses [28, 29], tuned mass dampers [30]-[32], structural frames [33], selection of scaled ground motion records [34], base isolation systems [35] and RC member mentioned in the introduction [20], 
[22]-[24].

In the optimum design of RC frames, different types of structural member (column and beams) with different design constraints (i.e. slenderness for column, reinforcement below balanced strains for beam) are in progress. For that reason, HS is modified with additional random stages, as seen in Fig. 1. Also, the local search part of the algorithm is modified since discrete variables are used in the practical design of RC members. Only fixed dimensions can be constructed in a construction yard. Also, reinforcements are produced in constant sizes.

In classical HS search, two optimization stages exist. After the randomly generation of initial values of design variables within a user defined range, the initial harmony memory matrix (HMM) is constructed. HMM is updated by generating new solutions according to the rules of HS. Musician can play new harmonies or they can also play favorite songs with small differences. Similar to this, new solutions from the whole range is generated in global search. As the local search, a new solution is searched around the existing ones with a possibility called harmony memory consideration rate (HMCR). At the end of all iterations, HMM including solutions as many as harmony memory size (HMS) is updated if a new solution is better than the worst ones in mean of the objective function. The objective function $(\mathrm{OF})$ of the present study is the total cost to minimize as seen in (1).

$$
O F=\sum_{i=1}^{n}\left(C_{e}\right)_{i} \quad \text { n:number of elements. }
$$

The cost of elements $\left(\mathrm{C}_{\mathrm{c}}\right)$ are as defined in (2).

$$
C_{e}=\left(A_{g}-A_{s t}\right) 1_{e} C_{c}+\left(A_{s t}+\frac{A_{v}}{s} u_{s t}\right) 1_{e} \gamma_{s} C_{s}
$$

In (2), $A_{g}, A_{s t}, A_{v}, u_{s t}, C_{c}, C_{s}, l_{\mathrm{e}}$ and $\gamma_{s}$ represents the area of cross section, the area of longitudinal reinforcement, the area of shear reinforcements spacing s, the length of shear reinforcements, the material cost of the concrete per $\mathrm{m}^{3}$, the material cost of per ton, the length of element and specific gravity of steel, respectively. All design constants are shown in Table I.

The local search is modified for the problem and the solution ranges are updated. The lower or upper bound of the ranges remains the same, but the other bound is changed with an existing solutions for an iteration.

\section{NUMERICAL EXAMPLE}

The two story two span frame model shown in Fig. 2 is optimized. The beams are loaded with trapezoidal distributed loads. The iterative analyses are done for maximum 20000 iterations and the total cost is penalized with $10^{6} \$$ if the design constraints are violated.

$\mathrm{D}$ and $\mathrm{L}$ represent the dead and live loads, respectively. In optimization, the unfavorable loading of live loads is also considered. The ratio of $a / l$ is $1 / 4$ and $a$ is the length of triangular loading and $l$ is the total length of loading distance.

The design constants are defined in Table I with the numerical values and the optimum results are presented in Table II and III for columns and beams, respectively. In optimization, the distances are assigned to the values which are the multiples of $50 \mathrm{~mm}$. The reinforcements are searched with $2 \mathrm{~mm}$ increments. $\mathrm{LJ}$ and RJ represent the left and right joints the elements.

TABLE I. DESIGN CONSTANTS AND RANGES OF DESIGN VARIABLES

\begin{tabular}{cccc}
\multicolumn{4}{c}{ TABLE I. DESIGN CONSTANTS AND RANGES OF DESIGN VARIABLES } \\
\hline Definition & Symbol & Unit & Value \\
\hline Range of web width & $\mathrm{b}_{\mathrm{w}}$ & $\mathrm{mm}$ & $250-400$ \\
Range of height & $\mathrm{h}$ & $\mathrm{mm}$ & $300-600$ \\
Clear cover & $\mathrm{c}_{\mathrm{c}}$ & $\mathrm{mm}$ & 30 \\
Range of reinforcement & $\phi$ & $\mathrm{mm}$ & $16-30$ \\
Range of shear reinforcement & $\phi_{\mathrm{v}}$ & $\mathrm{mm}$ & $8-14$ \\
Max. aggregate diameter & $\mathrm{D}_{\mathrm{max}}$ & $\mathrm{mm}$ & 16 \\
Yield strength of steel & $\mathrm{f}_{\mathrm{y}}$ & $\mathrm{MPa}$ & 420 \\
Comp. strength of concrete & $f_{c}^{\prime}$ & $\mathrm{MPa}$ & 25 \\
Elasticity modulus of steel & $\mathrm{E}_{\mathrm{s}}$ & $\mathrm{MPa}$ & 200000 \\
Specific gravity of steel & $\gamma_{\mathrm{s}}$ & $\mathrm{t} / \mathrm{m} 3$ & 7.86 \\
Specific gravity of concrete & $\gamma_{\mathrm{c}}$ & $\mathrm{t} / \mathrm{m} 3$ & 2.5 \\
Cost of the concrete per $\mathrm{m} 3$ & $\mathrm{C}_{\mathrm{c}}$ & $\$$ & 40 \\
Cost of the steel per ton & $\mathrm{C}_{\mathrm{s}}$ & $\$$ & 400 \\
\hline
\end{tabular}




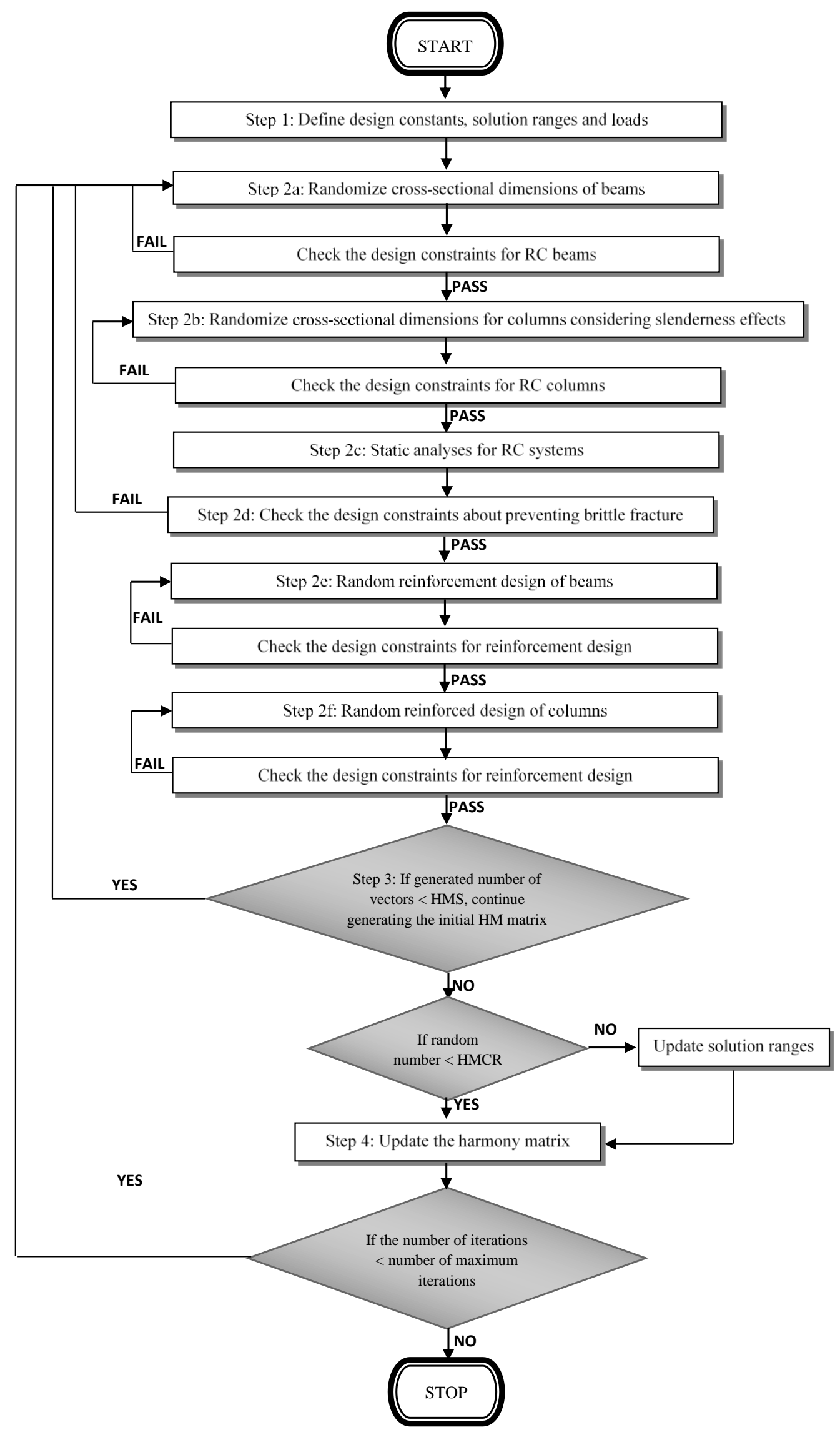

Fig. 1. Flowchart of methodology 


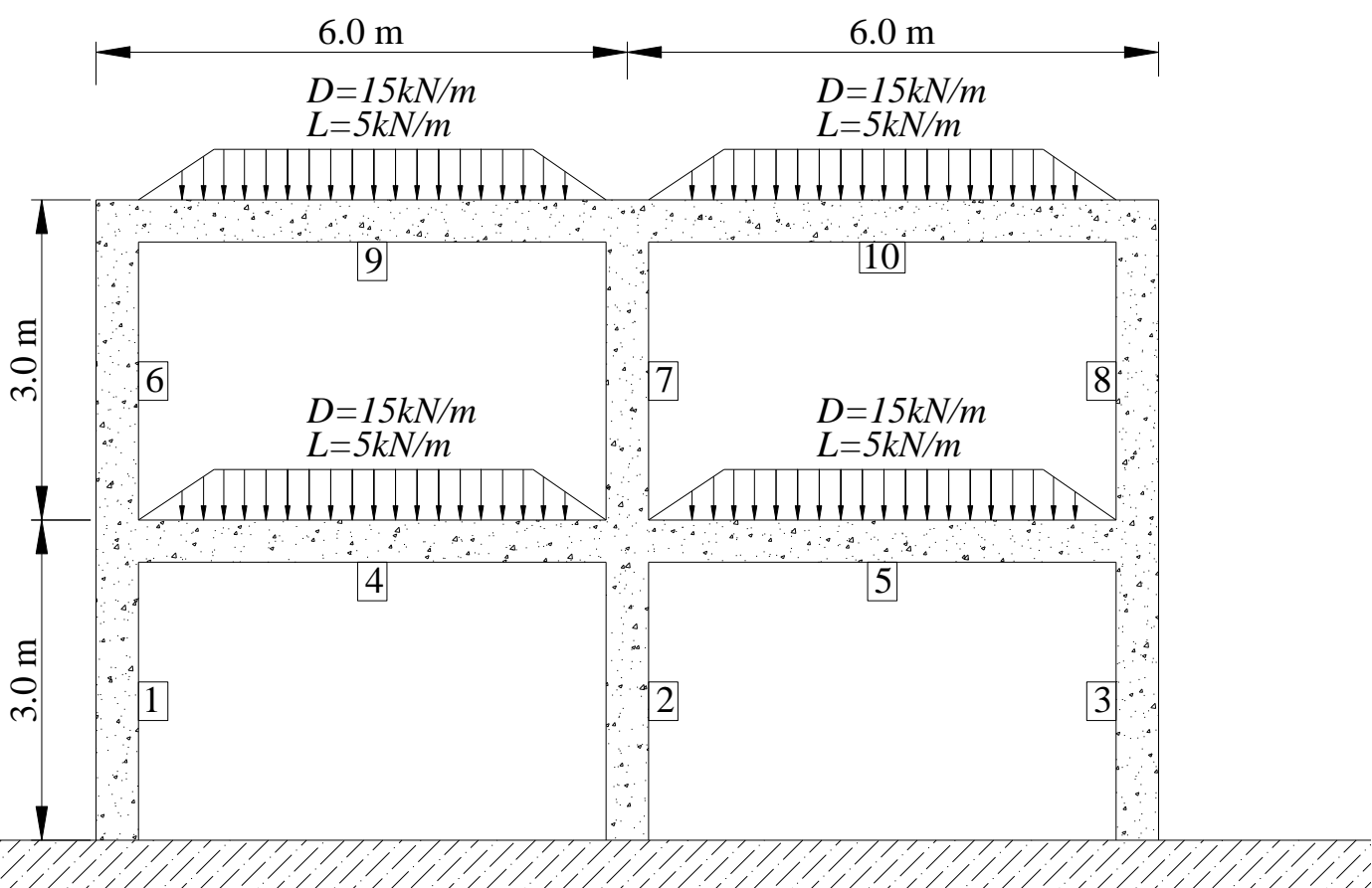

Fig. 2. Model of the numerical example.

TABLE II: OPTIMUM DESIGN OF COLUMNS

\begin{tabular}{ccccc}
\hline Element Number & $\mathrm{b}_{\mathrm{w}}(\mathrm{mm})$ & $\mathrm{h}(\mathrm{mm})$ & Bars in each face & $\begin{array}{c}\text { Shear reinforcement } \\
\text { diameter/distance }(\mathrm{mm})\end{array}$ \\
\hline 1 & 250 & 300 & $2 \Phi 10+2 \Phi 12$ & $\Phi 8 / 120$ \\
2 & 250 & 300 & $2 \Phi 10+2 \Phi 12$ & $\Phi 8 / 120$ \\
3 & 250 & 300 & $2 \Phi 10+2 \Phi 12$ & $\Phi 8 / 120$ \\
6 & 250 & 300 & $2 \Phi 10+2 \Phi 12$ & $\Phi 8 / 120$ \\
7 & 250 & 300 & $2 \Phi 10+2 \Phi 12$ & $\Phi 8 / 120$ \\
8 & 250 & 300 & $2 \Phi 10+2 \Phi 12$ & $\Phi 8 / 120$ \\
\hline
\end{tabular}

TABLE III: OPTIMUM DESIGN OF BEAMS

\begin{tabular}{|c|c|c|c|c|c|}
\hline Element Number & $\mathrm{b}_{\mathrm{w}}(\mathrm{mm})$ & $\begin{array}{c}\mathrm{h} \\
(\mathrm{mm})\end{array}$ & Bars in comp. section & Bars in tensile section & $\begin{array}{c}\text { Shear reinforcement } \\
\text { diameter/distance }(\mathrm{mm})\end{array}$ \\
\hline LJ4 & & & $1 \Phi 16+1 \Phi 22$ & $2 \Phi 26$ & \\
\hline 4 & 250 & 300 & $2 \Phi 12$ & $1 \Phi 14+1 \Phi 24$ & $\Phi 8 / 120$ \\
\hline RJ4-LJ5 & & & $2 \Phi 10+3 \Phi 14$ & $1 \Phi 30+1 \Phi 26$ & \\
\hline 5 & 250 & 300 & $2 \Phi 12$ & $4 \Phi 14$ & $\Phi 8 / 120$ \\
\hline RJ5 & & & $1 \Phi 16+1 \Phi 20$ & $1 \Phi 22+1 \Phi 28$ & \\
\hline LJ9 & & & 1Ф14+ 1Ф18 & $1 \Phi 14+2 \Phi 20$ & \\
\hline 9 & 250 & 300 & $2 \Phi 12$ & $1 \Phi 14+1 \Phi 26$ & $\Phi 8 / 120$ \\
\hline RJ9-LJ10 & & & $1 \Phi 14+2 \Phi 18$ & $1 \Phi 20+1 \Phi 24+1 \Phi 26$ & \\
\hline 10 & 250 & 300 & $2 \Phi 12$ & $3 \Phi 14+1 \Phi 16$ & $\Phi 8 / 120$ \\
\hline LJ10 & & & $1 \Phi 12+1 \Phi 20$ & $1 \Phi 14+1 \Phi 18+1 \Phi 22$ & \\
\hline
\end{tabular}

\section{CONCLUSION}

The proposed methodology is a feasible method for the cost optimization of RC frames. At the end of the optimization process, the optimum cost is 300.6193 \$. The user defined ranges are reasonable values for the design of $\mathrm{RC}$ frame and an engineer can choose a dimension from these values. If this situation is considered, every iteration of the proposed method may be a manual design of an engineer. The total costs of five iterations are 500.2729 \$, 467.1681 \$, $457.1243 \$, 454.6946 \$$ and $445.6569 \$$. In that case, the optimum design is useful to reduce the total cost by $39.91 \%$. In the future, the optimum design of space frame structures with the other metaheuristic algorithms will be investigated.

\section{REFERENCES}

[1] C. C. Coello, F. S. Hernandez, and F. A. Farrera, "Optimal design of reinforced concrete beams using genetic algorithms," Expert Syst. Appl., vol. 12, pp. 101-108, 1997.

[2] M.Y. Rafiq and C. Southcombe, "Genetic algorithms in optimal design and detailing of reinforced concrete biaxial columns supported by a declarative approach for capacity checking," Comput. Struct., vol. 69, pp. 443-457, 1998

[3] S. Rajeev and C. S. Krishnamoorthy, "Genetic algorithm - Based methodology for design optimization of reinforced concrete frames," Comput-Aided Civ. Inf., vol. 13, pp. 63-74, 1998.

[4] C. Lee and J. Ahn, "Flexural design of reinforced concrete frames by genetic algorithm," J Struct. Eng.-ASCE, vol. 129, no. 6, pp. 762-774, 2003 . 
[5] C. V. Camp, S. Pezeshk, H. and Hansson, "Flexural design of reinforced concrete frames using a genetic algorithm," J Struct. Eng. ASCE, vol. 129, pp. 105-11, 2003.

[6] V. Govindaraj and J. V. Ramasamy, "Optimum detailed design of reinforced concrete continuous beams using genetic algorithms," Comput. Struct., vol. 84, pp. 34-48, 2005.

[7] V. Govindaraj and J. V. Ramasamy, "Optimum detailed design of reinforced concrete frames using genetic algorithms," Eng. Optimiz. vol. 39, no. 4, pp. 471-494, 2007.

[8] F. Fedghouche and B. Tiliouine, "Minimum cost design of reinforced concrete T-beams at ultimate loads using Eurocode2," Eng. Struct., vol. 42, pp. 43-50, 2012.

[9] V. K. Koumousis and S. J. Arsenis, (1998). "Genetic Algorithms in Optimal Detailed Design of Reinforced Concrete Members." ComputAided Civ. Inf., 13, 43-52, 1998.

[10] D. P. Rath, A. S. Ahlawat, and A. Ramaswamy, "Shape optimization of RC flexural members," J Struct. Eng.-ASCE, vol. 125, pp. 14391446, 1999.

[11] M. Leps and M. Sejnoha, "New approach to optimization of reinforced concrete beams," Comput. Struct., vol. 81, pp. 1957-1966, 2003.

[12] M. G. Sahab, A. F. Ashour, and V. V. Toropov, (2005). "Cost optimisation of reinforced concrete flat slab buildings." Eng. Struct., 27, 313-322, 2005

[13] I. Paya, V. Yepes, F. Gonzalez-Vidosa, and A. Hospitaler, "Multiobjective optimization of concrete frames by simulated annealing," Comput-Aided Civ. Inf., vol. 23, pp. 596-610, 2008.

[14] C. Perea, J. Alcala, V. Yepes, and F. Gonzalez-Vidosa, and A. Hospitaler, "Design of reinforced concrete bridge frames by heuristic optimization," Adv. Eng. Softw., vol. 39, pp. 676-688, 2008.

[15] I. Paya-Zaforteza, V. Yepes, A. Hospitaler, and F. Gonzalez-Vidosa, "CO2-optimization of reinforced concrete frames by simulated annealing," Eng. Struct., vol. 31, pp. 1501-1508, 2009.

[16] C. V. Camp and F. Huq, "CO2 and cost optimization of reinforced concrete frames using a big bang-big crunch algorithm," Eng. Struct., vol. 48, pp. 363-372, 2013.

[17] B. Ceranic, C. Freyer, and R.W. Baines, "An application of simulated annealing to the optimum design reinfroced concrete retaining structure," Comput. Struct., vol. 79, pp. 1569-1581, 2001.

[18] V. Yepes, J. Alcala, C. Perea, and F. Gonzalez-Vidosa, "A parametric study of optimum earth-retaining walls by simulated annealing," Eng. Struct., vol. 30, pp. 821-830, 2008.

[19] C. V. Camp and A. Akin, "Design of retaining walls using big bang Big crunch optimization," J Struct. Eng.-ASCE, vol. 138, no. 3, pp. 438-448, 2012

[20] A. Kaveh and A. S. M. Abadi, "Harmony search based algorithms for the optimum cost design of reinforced concrete cantilever retaining walls," Int. J Civil Eng., vol. 9, no. 1, pp. 1-8, 2011.

[21] S. Talatahari, R. Sheikholeslami, M. Shadfaran, and M. Pourbaba, "Optimum design of gravity retaining walls using charged system search algorithm," Mathematical Problems in Engineering, pp. 1-10, 2012.

[22] A. Akin and M. P. Saka, "Optimum detailed design of reinforced concrete continuous beams using the harmony search algorithm," 2010.

[23] A. Akin and M. P. Saka, "Optimum detailing design of reinforced concrete plane frames to ACI 318-05 using the harmony search algorithm," in Proc. the Eleventh International Conference on Computational Structures Technology.

[24] G. Bekdaş and S. M. Nigdeli, "Cost optimization of T-shaped reinforced concrete beams under flexural effect according to AC 318," in Proc. 3rd European Conference of Civil Engineering, December 2-4 2012, Paris, France, 2012.

[25] ACI 318M-05, Building code requirements for structural concrete and commentary, American Concrete Institute, 2005.

[26] Z. W. Geem, J. H. Kim, and G. V. Loganathan, "A new heuristic optimization algorithm: Harmony search," Simulation, vol. 76, pp. $60-68,2001$.
[27] F. Erdal, E. Dogan, and M. P. Saka, "Optimum design of cellular beams using harmony search and particle swarm optimizers," $J$ Constr. Steel Res., vol. 67, no. 2, pp. 237-247, 2011.

[28] V. Togan, A. T. Daloglu, and H. Karadeniz, "Optimization of trusses under uncertainties with harmony search," Struc. Eng. Mech., vol. 37, no. 5 , pp. 543-560, 2011

[29] Y. C. Toklu, G. Bekdas, and R. Temur, "Analysis of trusses by total potential optimization method coupled with harmony search," Struc. Eng. Mech., vol. 45, no. 2, pp. 183-199, 2013.

[30] G. Bekdaş and S. M. Nigdeli, "Estimating optimum parameters of tuned mass dampers using harmony search," Eng. Struct., vol. 33, pp. 2716-2723, 2011.

[31] G. Bekdaş and S. M. Nigdeli, "Mass ratio factor for optimum tuned mass damper strategies," International Journal of Mechanical Sciences, vol. 71, pp. 68-84, 2013.

[32] S. M. Nigdeli and G. Bekdaş, "Optimum tuned mass damper design for preventing brittle fracture of RC buildings," Smart Struct Syst., vol. 12, pp. 137-155, 2013.

[33] Martini, K. (2011), Harmony Search Method for Multimodal Size, Shape, and Topology Optimization of Structural Frameworks, J Struct. Eng.-ASCE, 137(11), 1332-1339.

[34] A. H. Kayhan, "Selection and scaling of ground motion records Using harmony search," Teknik Dergi, vol. 23, no. 1, pp. 5751-5775, 2012

[35] S. M. Nigdeli, G. Bekdaş, and C. Alhan, "Optimization of seismic isolation systems via harmony search," Eng. Optimiz.

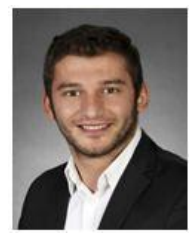

Serdar Ulusoy is a student of civil engineering $\mathrm{PhD}$ program of İstanbul University. $\mathrm{He}$ is working on structural optimization and Control. Up to now, the authored several papers about optimization of strucrtural Control and dynamic of structures interacting with soil in conference like $3^{\text {rd }}$ International conference on engineering and natural science and International conference on civil and environmental engineering.

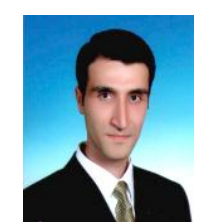

Gebrail Bekdaş is an associative professor, is researcher in structural control and optimization at Istanbul University. He obtained his DPhil in Structural Engineering from Istanbul University with a thesis subject of design of cylindrical walls. He co-organized the 15th EU-ME Workshop: Metaheuristic and Engineering in Istanbul. In optimization, he organized several mini-symposiums or special sections in prestigious international events. He co-edited Metaheuristics and Optimization in Civil Engineering published by Springer in 2016 and he is one of the guest editors in 2017 special issue of KSCE Journal of Civil Engineering. He has authored more than 100 papers for journals and scientific events.

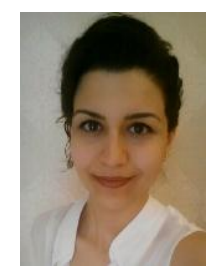

Sinan Melih Nigdeli is an associative professor, is researcher in structural control and optimization at Istanbul University. He obtained his DPhil in Structural Engineering from Istanbul Technical University with a thesis subject of active structural control. He co-organized the 15th EU-ME Workshop: Metaheuristic and Engineering in Istanbul. In optimizationand structural control, he organized several mini-symposiums or special sections in prestigious international events. He co-edited Metaheuristics and Optimization in Civil Engineering published by Springer in 2016 and he is one of the guest editors in 2017 special issue of KSCE Journal of Civil Engineering. He has authored more than 100 papers for journals and scientific events.

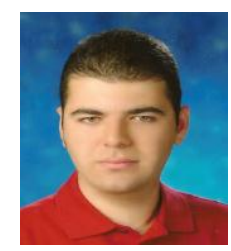

Aylin Ece Kayabekir is a student of civil engineering $\mathrm{PhD}$ program of İstanbul University. She is working on structural optimization. Up to now, the authored several papers about optimization of RC retaining walls, RC shear walls, frames, carbon fiber reinforced polymers and dynamic of structures interacting with soil in conference like $7^{\text {th }}$ European conference of civil engineering, International science symposium 2016, $3^{\text {rd }}$ International conference on engineering and natural science and International conference on civil and environmental engineering. 